\title{
SUFIJOS ÁTONOS EN EL MEDITERRÁNEO OCCIDENTAL
}

En 1905 fijé mi atención por primera vez en estos sufijos átonos, considerándolos como un grupo morfológico de carácter homogéneo, compuestos de dos sílabas, constituídas por una vocal postónica $a$ (o a veces también $i, e, o$ ), más consonảnte $r, l, n$ o $g$, más vocal final de femenino $a$, o también de masculino $o$; estas varias formas son alguna vez intercambiables en el mismo vocablo. Me preocupaba sobre todo el negar la modernidad que se atribuía a estos sufijos; fundándome en ejemplos de tiempos romanos ( $\mathrm{Brac}$ a ra), o preliterarios, anteriores al siglo XII (córnago), o bien ejemplos suministrados por los más antiguos textos literarios (gállara), afirmaba que sus orígenes se hallaban "en el período primitivo del romance", "en tiempos prehistóricos del habla vulgar", pero dudaba entre creer que fuesen de formación románica, por analogía con otros proparoxítonos latinos, $o$ bien que fuesen de origen probablemente extralatino ${ }^{1}$.

Más tarde, en 1926, reconocía que los sufijos latinos $-\breve{u} l u$, $-\mathbf{i} \mathrm{c} u$ podían haber determinado los sufijos átonos románicos '-ola, '-ega, '-iga (ejemplos: del siglo x, Caórnega; del xI, Tolédola, Piédrola, Espóñola, etc.), pero no hallaba razonable un modelo latino para '-ara, '-ala, '-ago, '-aga, '-ano, '-ana,' '-amo (ejemplos: del siglo I, $\mathrm{B} \mathrm{r} \mathrm{a} \mathrm{că} \mathrm{a}$; del Ix, várgano, Hórcanos; del $\mathrm{x}$, Káscaras, sárçano, sótalo; del xi, córnago, abrécano), y concluía que hubieron de existir sufijos prelatinos en que dominaba la a postónica, y que estos sufijos debieron preponderar en España más que en otros paises románicos $^{2}$.

Adolf Schulten, en 1914 y 1923, señala la presencia de muchos topónimos -ă $\mathrm{r}$ a en el Norte de Âfrica, y nota la difusión de éste, que llama "sufijo africano", por la Sicilia sicana y por Hispania ${ }^{3}$.

Wilhelm Meyer-Lübke en 1925, sin utilizar el estudio mío, enu-

1 "Sufijos átonos en español", en Festgabe für A. Mussafia, Halle, 1905, págs. 368-40o, particularmente pág. 385; Manual de gramática histórica española, Madrid, 1905, pág. 147.

${ }^{2}$ Origenes del español, 1926, $\$ 61$ bis. Suprimido en la $3^{a}$ ed., 1950, porque la materia exigía mucho mayor desarrollo.

3 Schulten, Numantia, 1914, pág. 57, y en PWRE, 1929, s. v. Sicani. En 
mera varios topónimos '-ana, '-ano en España y en Cerdeña. En cuanto al sufijo '-alo de Nuévalo, Grávalos, no sabe si es antiguo o no; sin utilizar la opinión de Schulten, piensa que los topónimos '-ara, '-era pueden ser ibéricos o celtas, pues el céltico conoce un sufijo'-ara; el río $\mathrm{T}$ a $\mathrm{m}$ ă $\mathrm{r}$ is de Galicia se relaciona con el pueblo de los Supertamarici, que parecen no ser celtas, según el pasaje de Plinio donde se los menciona. Como cosa aparte examina el sufijo '-ar, que en vista del Aránsar de Lérida debe de ser el sufijo vasco - ar, señalado por Uhlenbeck (RIEV, III, 1909, pág. 6). No trata de' '-aga $a^{4}$.

Vittorio Bertoldi, en 1937, estudia fundamentalmente el principal de estos sufijos, '-ara, '-ar, en toda su extensión geográfica. En muchas comarcas de la cuenca del Mediterráneo se repiten nombres toponímicos y comunes sin duda prehelénicos, prelatinos y precélticos, provistos de la terminación '-ara, uno de cuyos significados es el colectivo o abundancial, bien establecido en comparación con los plurales $r$ existentes en algunas lenguas del Cáucaso y con los colectivos vascos en -ar, del tipo legar 'grava, cascajo'. Nota Bertoldi el gran arraigo de este sufijo en las dos zonas extremas, las dos penínsulas opuestas del Mediterráneo: España, con multitud de topónimos Egăr a, N a c că ra, B ra că ra, Láncara, Tábara, etc., y la Anato-

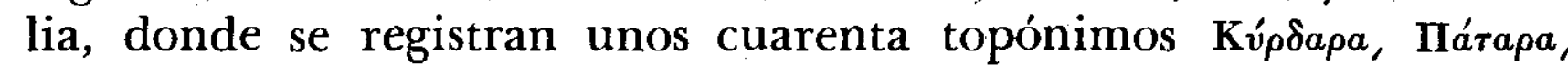

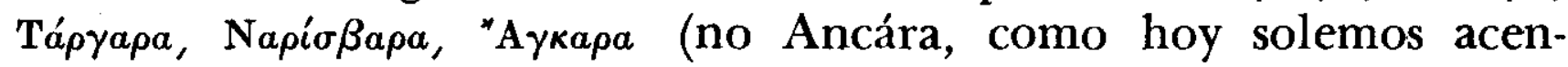
tuar), etc., uniéndose estas dos zonas marginales con formaciones semejantes diseminadas por los países intermedios del Tirreno y del Egeo, de lo cual va examinando ejemplos en Licia, en Lidia, en Etruria y otras regiones itálicas, en Sicilia, en Cerdeña y en vasco ${ }^{5}$.

Max Förster, en 1941, califica el sufijo ' -ar de protocéltico o precéltico, como formativo de nombres de ríos, y tiene $\mathrm{T}$ a $\mathrm{m}$ ă $\mathrm{r}$ a como hidrónimo céltico ${ }^{6}$.

Johannes Hubschmid junior, en 1943, estima que el estudio de Bertoldi no puede probar que el sufijo colectivo '-aro del céltico y aun del irlandés provenga de las lenguas mediterráneas preindoeuropeas, y así tiene por sufijo de origen céltico el sufijo de láparo y demás voces portuguesas ${ }^{7}$.

Aprovecharé todas estas opiniones en el curso del siguiente esbozo.

Numantia cita sólo como topónimos '-ara en África: M a ka ras, B i r a csaccara y $\mathrm{N}$ arragara (sic).

4 MeYeR-LüBKE, "Zur Kenntnis der vorrömischen Ortsnamen", en HMP, I, págs. $75,77,79$ y 80 .

5 Bertoldi, "Plurale mediterraneo in residui fossili", en Mélanges Jacq. Van Ginneken, Paris, 1937, págs. 157:169.

- Förster, Der Flussname Themse, München, 1941, págs. 408-410 y 948, 406 , etc.

"Hubschmid, "Bezeichnungen für 'Kaninchen"” etc., en la Miscelánea Jakob Jud, Romanica Helvetica, XX, 1943, pág. 250, nota, refiriéndose a la pág. 163, nota 1, de BerToldi. 
En él deseo mostrar que '-ar, el más importante sufijo, perteneciente sin duda a lenguas muy diversas, tiene su principal trayectoria histórica no aislado, sino formando con '-an, '-al, '-ag un conjunto morfológico. Deseo indicar también el arraigo de ese conjunto en el Mediterráneo occidental. Entro con gran contrariedad en un tema tan oscuro y resbaladizo, sin pretender ahondar en él, pero viendo que es necesario llamar la atención sobre esta materia tan capital como descuidada en el estudio de la toponimia y de la lengua común.

\section{ANalogías AFro-europeas}

Lo que primero nos importa notar es que los topónimos '-ara o '-ar son abundantísimos en el Noroeste de África lo mismo que en España y en Italia.

En el África Menor, en la Numidia y en la Mauretania se hallan por ejemplo: Ca nnar, Z u c chăra o Z u gar, A m ma edăra,

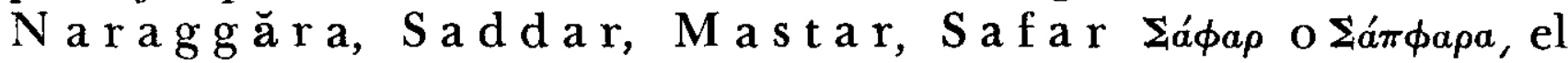
río $\mathrm{Macar}, \mathrm{Sufasar}$ y $\mathrm{Succ}$ abar próximas entre sí y ambas sobre el río Us a r, el lago Sírapa, etc.

En la España antigua y en la moderna son innumerables los pueblos que llevan nombre de este tipo, según indicaremos, pero antes de nada debemos adelantar que en toda la Península predomina la tendencia a la apócope '-ar, como predomina en los ejemplos del Noroeste africano, y predomina enormemente en Andalucía. Baste aquí decir a modo de ejemplo que entre los cuarenta y nueve pueblos, villas, lugares y aldeas que formaban el antiguo partido de las Alpujarras, pertenecientes hoy a las provincias de Granada y Almería, hay diez del tipo Láujar, Timar, Canjáyar, Ujijar, etc. ${ }^{8}$; esto es, más de un $20 \%$ de los pueblos alpujarreños llevan nombre en '-ar, y sólo uno de los diez, Cástaras, no es apocopado, y esto por ser un plural.

Los topónimos sin apócope abundan en la España antigua y en la moderna. He aquí ejemplos interesantes:

N a ccăra e en Avieno, laguna, probablemente la Albufera de Valencia. - C a pă r a Itinerario de Antonino, G a p p a r a Anónimo Ravennate, Kámapa Tolomeo, ciudad de los Vettones, hoy Ventas de Cáparra Cáceres ${ }^{9}$. - E $\mathrm{g}$ a $\mathrm{r}$ a en los Ilergetes. - H a c $\mathrm{t}$ a $\mathrm{r}$ a Itinerario de Antonino. - Káscaras en documento de 956, lugar hoy des-

8 Madoz, Diccionario geogr., vol. II, pág. 199. Sólo a uno de los nombres, Almegijar, se le señala etimología árabe (M. Asín, Contribución a la toponimia árabe, 1940, pág. 68), etimología nada convincente por su vocalismo disconforme. En las págs. 149 y 150 Asín sospecha etimología árabe para otros dos de los diez pueblos (Beninar, Atalbéitar), pero no la encuentra, a pesar del aspecto árabe que superficialmente revisten esos dos nombres.

9 Madoz, vol. VIII, págs. $5^{6} 5^{a}$ y $5^{66 a}$; Holder, Alt-celtischer Sprachschatz, vol. II, col. 671; España sagrada, vol. XIV, 1786, pág. 55; E. SAavedra, Discursos ante la Academia de la Historia, 1862, pág. 8o. 
conocido en León ${ }^{10}$; compárese sin sufijo Casco, Cascas en Galicia y Portugal; Cascales apellido; vasco kascarr 'cráneo'.-Záncara Ciudad Real; sin sufijo Zanca Pontevedra. - T a b a $\mathrm{r}$ a en manuscritos latinos del siglo x, Tábara Zamora; compárese Tabaretta refugio en los Alpes de Bolzano, Tavarone caserío en la provincia de Génova. - Lángara pueblo de Álava, citado en el año $1025^{11}$, quizá el moderno Langarica; comp. Langarabide, esto es 'camino de Lángara', término de Arbulo (Álava) (véase RIEV, XXV, 1931, pág. 294). Fuera de España Lángaro en Calabria; un antropónimo ilirio $\Lambda a ́ \gamma \gamma a \rho o s$ (Schulze, Eigennamen, pág. 119). El simple sin sufijo, Langa, se repite en Ávila, Cuenca, Soria, Zaragoza; Languilla Segovia, y en país vasco, Langaondo (esto es 'junto a Langa'), término de Oyarzun (Guipuzcoa), con derivados Langosto, Langayo, Langata, etc.; lo mismo en Italia, varios Langa en Liguria, Piamonte y Emilia ${ }^{12}$, con derivados Langosco, Langasco, etc. Y dada la alternancia de sorda y sonora en posiciones iniciales y tras nasal o líquida, que se observa en vasco y en otras lenguas primitivas ${ }^{13}$, es de asociar aquí Láncara en Lugo (cuatro lugares) y en León. Este, pues, parece ser uno de los vocablos de más arraigo toponímico en los pueblos occidentales de sustrato precéltico y prelatino, identificable con el vasco langa, lanka 'traviesa, portillo, escaño', significados, todos tres, que se usan como topónimos en España. - B r a c ă r a, Gándara y otros que luego citaremos. - Cámpara Coruña (dos lugares); vemos aquí el sufijo prelatino aplicado al femenino adjetival de c a m p s, asturiano campa 'terreno llano, sin árboles', 'escampado', topónimo Campa, la Campa Lugo, Oviedo, Vizcaya; y en Italia, Campa Basilicata.

Los topónimos con apócope son, como hemos dicho, incontables. Enumero sólo alguno que otro: Íscar Valladolid, fscara en Cerdeña ${ }^{14}$, * I s c ă r a nombre del que proceden Hisscar, Ischer nombres de ríos en Bélgica y Alemania ${ }^{15}$.-Tiétar río de Cáceres; sin sufijo $\mathrm{T}$ e $\mathrm{t} \mathrm{u} \mathrm{m}$ río, hoy Têt en la Galia Narbonense ${ }^{16}$. - Andújar Jaén, probablemente de un Andusia como el de la Narbonense, hoy Anduze ${ }^{17}$. - Hijar Santander, Teruel, Albacete. - Mondéjar Guadalajara, Mo. nóvar Alicante, Mondújar, Montejicar Granada, Huévar Sevilla, Al. cuéscar, Piñuécar, Azuébar, Tuéjar, etc., etc.

En Sicilia occidental (la sicana o ibérica), M a că ra, Indăra, M a ză ra Mázara; H y c că ra, llamada así, en Ateneo, por abun-

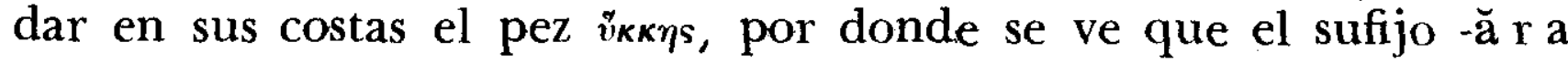

10 R. Escalona, Historia del monasterio de Sahagún, 1782, pág. 4oo.

11 Cartulario de San Millán, ed. del P. Serrano, 193o, pág. 103.

12 Berthelot, "Les Ligures", en la Revue Archéologique, II, 1933, pág. 289.

13 Fenómeno estudiado por Bertoldi, "Problèmes de substrat", en BSLP,

XXXII, 1931, págs. 134 y sigs. y 145 y sigs.

14 Acento inicial supone-Bertold, Mélanges Van Ginneken, pág. 165.

15 Holder, y Zeit. f. celt. Philol., XX, pág. 457.

16 Asocia los dos nombres P. Fouché en RHi, LXXXI, 1933, pág. 340.

${ }^{17}$ Holder, Schuchardt y Meyer-Lübe quieren explicar Andujar por * Andura, sin adecuación fonética; se apoyan en la inexacta creencia de 
poseía un valor colectivo ${ }^{18}$; además, es de citar el dẹrivado $\mathrm{C}$ a s s ar i a (el Ravennate), junto a varios lugares llamados hoy il Cássaro. En la Sicilia oriental (la de los sículos) tenemos el riachuelo A s inăr u s que desemboca en el mar, al Sur de Siracusa; y en el Norte, en el mar Tirreno, la isla L i pă $\mathrm{r}$ a, hoy isole Lipari; entre los topónimos actuales, Bifara, Cósaro, Cállari.

En Cerdeña citamos en primer lugar a Ússara, a la vez que el sim-

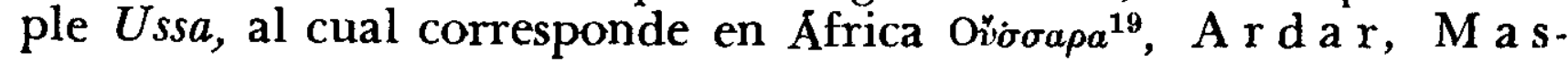
ca r, Nurka r, Ardara, Máscari río, Argara, Bártara, Cújaru, Ovara, Sárdara, Úccari, Zéppara, Iscara río, como el pueblo ya citado de Valladolid, Sássari derivado de Sasso, Mándara al Sureste de Mandas, Cúccaru, etc.

En Córcega Nisara, Pázzara, Súbara, Sáparo, con el apelativo sápara 'gruta' (el S a f a r, S a p p a r de Mauretania), Tónnari, etc. ${ }^{20}$

En Italia Ta nărus Tánaro, río de Liguria afluente del Po; T a mărus Támmaro en el Samnium; Fa rfărus río de los Sabinos afluente del Tíber; Párparo Puglia, Diégaro Ravenna, derivado del topónimo bastante común Diego, Dieco; Cúccaro topónimo repetido, derivado de Cucco, común sobre todo como nombre de montes, con el apelativo cucco (en España, el Cucalón de 'Teruel postula un ${ }^{*}$ Cúcalo, con el sufijo -alo de que luego hablaremos); Lóngara a la vez que Longa; Bórgaro Piamonte; Lámbara, Cóbbaro, Ongaro, etc.

No sabemos si todos estos nombres pertenecen a una misma categoría morfológica, y la misma duda cabe respecto a topónimos de otros países occidentales (Holder registra en Galia A vă ra, S a văr a, L a tă ra, T ěvă ra), pero siempre, por cima de esta duda, la mayoría de los casos aquí reunidos quedará atribuíble a una primitiva lengua mediterránea.

Tiene particular valor el hecho de que en los países examinados nos han salido al paso lugares de Córcega y de Cerdeña homónimos con otros lugares africanos. Homónimos así podemos observar también en España. $\mathrm{C}$ a $n$ n ă $r$ era el nombre de un promontorio que, según el Itinerario de Antonino, estaba al Oriente de la Mauretania Tingitana. Frente a él, en España, está la villa de Cáñar (Granada), en la falda meridional de Sierra Nevada. Se trata sin duda del sustantivo ca n n a 'caña, garganta' en el sentido topográfico, pues el Cáñar granadino está "en medio de un pequeño desfiladero" 21.

que la inscripción donde ocurre el adjetivo Andurens is fué hallada cerca de Andújar.

18 BERTOLDr, Mél. Van Ginneken, pág. 166, y BSLP, XXXII, ı931, pág. 124;

RibBezzo en la Rivista Indo-Greco-Italica, IV, 1920, pág. 67.

19 Bertoldi, Mél. Van Ginneken, pág. 165.

${ }^{20}$ G. BotTiglioni, Elementi prelatini nella toponomastica corsa, 1929, págs. 16 (nota 2), 20, 21, 45 y 87 .

${ }_{21}$ MADOz, vol. V, pág. 485; come curiosidad añado la circunstancia de que 
El sufijo '-ar lleva aquí un valor colectivo o plural, como el plural Cannae, Canne bastante repetido en el Sur de Italia, en Sicilia, Cerdeña y Córcega, así como en Fspaña Cañas, las Cañas, cuyo plural aludirá en unos casos a las angosturas del terreno y en otros a la abundancia del vegetal c a n n a; el C a n n a e de la famosa batalla de Aníbal está en terreno montuoso y roqueño que domina la llanura del Ófanto. Pero sea de esto lo que quiera, debemos sentar que no son necesariamente tardíos, como pudiera pensarse, los topónimos con base кávva c a n n a en las regiones occidentales del Mediterráneo.

Por lo demás, la coincidencia afro-hispana $\mathrm{C}$ a n n ă $\mathrm{r}$ nos hace pensar en otra. En el África Menor, al Sur de Cartago, estaba el ya citado Z u c c h ă r a o Z u gă r, y en España, no lejos de Cáñar está Zújar, nombre que se repite en Granada y en Badajoz.

\section{VALOR COLEGTIVO DEL SUfIJo '-ar}

El sentido colectivo o plural de este sufijo, bien estudiado por Bertoldi, se hace patente sobre el terreno de España en la Cuétara, caserío de la parroquia de Linares (Ribadesella, Oviedo), situado al borde de dos prolongadas crestas rocosas paralelas, coronadas por muchos cuetos o picachos (el cuetu'l Emprunu, el cuetu'e la Ventana, el cuetu'l Ramu, etc.); la Cuétara, pues, es sinónimo de Cuetas, Cuetos, topónimos usados en Asturias, Galicia y Portugal junto al singular Cueto, Coto ${ }^{22}$.

C o 11 a $\mathrm{r}$ en una crónica latina hacia $1130^{23}>$ Cuéllar Segovia, Salamanca; la de Segovia "situada entre varias colinas" (MADOZ); de collem + collum (Origenes del español, $\$ 855$ ); es, pues, de igual significado que el plural los Cuellos Jaén, Collos, Colles Portugal.

Almuñécar ${ }^{24}$ Granada, "situada sobre una colina, detrás de la cual se eleva una cordillera de escarpadas sierras en forma de anfiteatro" (MADOz); comparable al plural Muñecas Soria, "situado en la embocadura de una hoz", las Muñecas León, "situado a la falda de los cerros que bajan del puerto del Pando". El nombre común muñeca 'hito, mojón de piedra' es un derivado del simple Muño

desde Cáñar se divisa el Mediterráneo y en los días serenos "hasta las costas de Berbería" según Madoz; los dos Cáñar están a la vista el uno del otro.

${ }^{22}$ Véase mi artículo sobre " $\mathrm{C}_{Q} \mathrm{t} t \mathrm{o}, \mathrm{C}_{Q} \mathrm{t}$ t a" en $R o m P h$, VI, 1952-53, págs. 1-4, y J. Hubschmid, “Asturisch cuetu...”, ibid., págs. 190-198.

${ }^{23}$ Crónica de Pelayo Ovetense (B. N. M., ms. 1513); España sagrada, vol. XIV, pág. 488.

24 La explicación de Yaqūt sobre la forma Almunekkab 'el pueblo al que se le da la espalda' (Asín, Contribución a la toponimia árabe, pág. 71) es sin duda una etimología popular, arbitraria por la $n$ sencilla, por la $b$ final y por el extraño sentido. 
Oviedo, del que también derivan Muñón Oviedo, Muñana Ávila; en Italia Mugnone, Mugnana. Como nombre común, muñón se conserva en muchas lenguas; en asturiano significa también 'mojón' además del significado corriente en el castellano muñón, catalán munyó, francés moignon. El simple toponímico Muño es la voz mediterránea * m u n n o 'prominencia', vasco muño 'cerro, otero' $(R E W, 5747$, etimología latina inexplicante).

Galáchar Almería, sitio de varios galachos o barranqueras. - Estépar Burgos, sitio donde abundan las estepas, igual significado que Estepár.

En los otros sufijos veremos también muestras del significado colectivo.

\section{Gándara, Cándala, Cándana Y OTRAS EQUIVALENCIAS}

Gándara, noventa y cinco localidades con este nombre en el Nomenclator de las cuatro provincias gallegas; Gandra, doce en Coruña y Pontevedra; Granda, cuarenta y tres en Lugo; Graña y Granja en Orense, varios; La Gándara León; La Gándara, garganta de montaña con canchales, y río de la Gándara afluente del Asón (Santander) ${ }^{25}$; diminutivo Gandariña y Gandarela Galicia; Gandarilla Santander; Gandra, ciento cuarenta y siete en la Chorografia de Portugal de J. M. Baptista; Gandarinha, Gandarella más de treinta en Portugal. Es el topónimo más frecuente en el Noroeste de la Península; desconocido fuera de allí. Respondiendo a esta limitación, el apelativo gándara 'tierra baja, inculta y llena de maleza' no es conocido en castellano, y no entró en el Dicc. Acad. hasta la $11^{\text {a }}$ edición (1884), procedente de dialectos del Noroeste. En Galicia, gándara 'maleza, monte bajo, inculto y llano' (VallaDARES); en Portugal gándara, gandra 'terreno arenoso, estéril, cubierto de plantas agrestes; glera del río Mondego; rama seca de matorral', gándaros 'pedazos de urces secas' ${ }^{26}$. La metátesis de ese gandra es el asturiano granda 'rasa, terreno pedregoso e inculto, de gran extensión' (RATo), de donde el topónimo Granda, la Granda, Grandarrasa (más de cuarenta en el Nomenclator de Oviedo, de 1894), metátesis extendida también por la vecina provincia de Lugo, Granda, Grandela (más de treinta, y sólo nueve Gándara en el Nomenclator de 1893); Gandarias, Gandaran Vizcaya, etc.

El simple ganda vive en los dialectos alpinos, significando 'canchal, pedregal, cascajar', con topónimos Ganda Bérgamo, Ganna varios $^{27}$. Este topónimo simple en España lo hallo únicamente en

25 Este topónimo es señalado por Bertoldi en el art. cit. de BSLP, pág. 106.

26 El significado de 'glera', en el Dic. de VIEIRA; el de 'pedaço de estêva seca' en Figueiredo; gândaros 'pedaços de urzes secas' en Castro Laboreiro (Vianna): $R L u$, XIX, 1916, pág. 276.

$27 R E W, 3670$. La base ga nd a-ca nda está estudiada muy ampliamente por BERTOLdr, art. cit. de $B S L P$, págs. 95 y sigs. Véase también $\mathrm{C}$. BatTrsti en Studi Etruschi, VIII, 1934, pág. 184 . 
país vasco, Ganda como apellido, Gando, con otras terminaciones Gandaitz, Gandiaga (RIEV, XXII, 1928, pág. 621). Derivados son también Gandia Valencia, Gandesa Tarragona, cuyos nombres responden a la parte de terreno pedregoso, vecino al mar, que estas dos poblaciones tienen, etc.

Dada la vacilación entre consonante sorda y sonora que se observa en lenguas primitivas mediterráneas, el topónimo de que tratamos

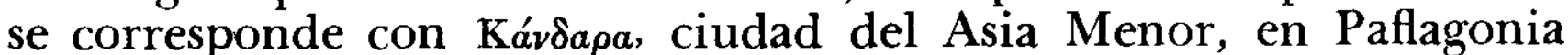
(Bertoldi, BSLP, XXXII, 1931, págs. 115,145 y 134-144), y éste se asocia al nombre étnico $G$ a n dăr i que Mela aplica a un pueblo del Cáucaso.

En Europa, entre varios homónimos, citaremos $\mathrm{C}$ a nd a ra en documento latino del año 790 , hoy Kander, río que corre junto a Lörrach (Baden) (BerToldi, ibid., pág. 111); y en Italia il Cándaro, caserío en las montañas de la Basilicata. En Portugal se conserva como nombre común cândaro 'rama seca de árbol' (Villa Real, Tras-os-Montes: $R L u, \mathrm{XI}, 1908$, pág. 30o), donde vemos continuarse la asociación de los dos significados de gandara: 'pedregal, peñascal' y 'matorral, leña seca'. - El simple Canda es el nombre de un desfiladero donde se amontonan formidables bloques de peñascos, formando un vasto e imponente canchal, en el Apenino tosco-emiliano (Bertoldi, art. cit., pág. 114); y Canda o la Canda designa otros poblados o montañas en los Alpes y en los Apeninos.

A este Cándara de Italia corresponden en el Norte de España Cándana Oviedo, la Cándana León, Cándena Miranda de Douro ${ }^{28}$, Cándano Oviedo (cuatro lugares). Como nombre común cándanu significa 'rama seca de árbol' (Colunga, Cabranes) ${ }^{29}$, 'posos que deja un líquido en la vasija; sedimentos aluviales que deja un río' (Salamanca $)^{30}$, y también el derivado candal sitio de tierra blanquecina' (?) (Asturias) ${ }^{31}$. - Este y otros derivados viven en la toponimia: Candanal Oviedo (cuatro lugares; el de Villaviciosa dice el Diccionario de MADOZ que está "en un estrecho valle que se prolonga de Norte a Sur, dominado por dos grandes montañas en igual dirección"); Candal varios en Portugal y Galicia; Candanero tres en Oviedo, dos en León, uno en Zamora; Candedo, varios en Galicia y Portugal; y Candendo, Candaedo en Galicia varios; Candanosa Oviedo (cinco lugares), Candenosa Santander, Candosa, Candoso varios en Galicia y Portugal.

Al lado del nombre común cándano de Asturias, cândaro de Tras-

28 J. Leite de Vasconcellos, Philologia mirandesa, vol. II, 1901, pág. 17.

29 Usual en Libardón (Oviedo) (B. Vigón, Vocabulario de Colunga, suplemento); cándanu 'rama seca que aún está en el árbol' (M. J. Canellada, El bable de Cabranes, 1944).

30 LaMano, Dial. salmantino. Unamuno me comunicó la frase usual en Vilvestre: "bajar o ir a cándanos, es ir a coger los objetos que el Duero deja en sus orillas, cuando cesan sus avenidas".

31 Vocabulario bable de RATo; esta definición, nada precisa, obedece sin duda a prejuicio etimológico; la definición de Rato hace pensar en can did u s a LeIte, Philologia mirandesa, vol. II, pág. 17. 
os-Montes; hay cándalo 'rama seca de árbol', particularmente usado en plural para designar la leña seca que se recoge para encender el fuego (Valladolid, Segovia, Soria y Teruel); también en Tras-osMontes a la vez que el citado cândaros (o candros) se usa candos ( $R L u, \mathrm{XI}, 1908$, pág. 300) ; el mismo cándalo significa 'rama deshojada, panoja desgranada' en Cantalapiedra, prov. de Salamanca (LAMANO), 'árbol o arbusto requemados, leño grueso trashoguero; variedad del pino' en Andalucía (Alcalá Venceslada); también cándalo tiene el significado de 'pino seco' según el cordobés Barahona de Soto $^{32}$. En la toponimia escasea: los Cándalos Pendueles, en Asturias; la Candaliega Oviedo.

Hallamos también -como Gándara, Cándala, Cándana- tres equivalencias primitivas en el nombre de la segunda ciudad capital de la Galecia. La forma oficial y culta del sufijo es '-ara, y las formas divulgadas popularmente son '-ala y '-ana.

B rā c ăr a A u g u st a (Plinio, Tolomeo, etc.), capital del convento entre Duero y Miño, nombre alusivo a la b rāca, calzón largo, habitual en la mayor parte de los celtas. Los habitantes de esa región, en vez de $\mathrm{B} \mathrm{r} \mathrm{a} \mathrm{c} \mathrm{a} t \mathrm{i}$, como se llamaba a los galos de la Narbonense, recibían la denominación de B rācări; el sufijo '-ara en la ciudad de Bracăra tiene, pues, valor adjetivo, semejante al que califica a la Narbonense, llamándola Galli a B r a c a ta; $\mathrm{B}$ r a c ă $\mathrm{r}$ a es la ciudad de los hombres vestidos de bragas. También en España se usó, como nombre personal, B rā c ă ru s ${ }^{33}$.

Se empleó a la vez la variante * B racăn a, que parece fué popularizada al Oriente de la región bracarense, ya que fué la forma perpetuada en Castilla, para designar la ciudad galaica, hasta en el siglo xiv, antes que se impusiese el portuguesismo Bragaa Braga. En la Primera crónica general, hacia 1289, se designa siempre la capital portuguesa con el nombre de Brágana $^{34}$, e igualmente en la Tercera crónica general, de la segunda mitad del siglo $\mathrm{XIV}^{35}$. La misma variante se usó en otra región céltica que descubrimos en el Sureste de la Península, en la cuenca del Genil, donde hoy una aldeíta de fllora (Granada) lleva el nombre de Brácana, con la $c$ conservada sorda por cultismo mozárabe; curiosísimo arcaísmo toponímico que, confirmando el gran arraigo de la forma con - $n$ - en el centro de España, muestra además la igualdad del chocante vestuario entre los celtas de la Galecia y los del pequeño grupo de la Bética.

Otra forma popular de B r a c ă r a es B r a c ă la, algo usual en la Edad Media, con el adjetivo B r a g a le n s is, de donde el nombre

32 Diálogos de la monteria (fines del siglo xvi), ed. Bibliófilos, pág. 401.

33 J. Perin, Onomasticon, vol. I, 191 , pág. $278 c$.

34 Págs. 196b, 295b, 296a, etc., hasta doce veces. Consultado por mí en 1903, David Lopes me escribía: "Não conheço a forma Bragana. As pessoas que consultei sobre ella, entre outras o sr. dr. Leite de Vasconcellos, nada me souberam, nem encontrei tal forma nas leituras a que procedi".

35 Véase la edición de Ocampo, Zamora, 1541, fols. 193d, 194d, etc. 
portugués corriente Bragaa en la Edad Media y Braga moderno ${ }^{36}$. El mismo topónimo Braga se repite en Villa-Real, es decir, dentro del territorio bracarense, y se repite fuera de ese territorio, en Coimbra, Guarda y Santarem.

Un ejemplo muy antiguo y muy copioso de la aplicación del sufijo prelatino a un tema latino, lo incluímos ahora, porque también nos ofrece la alternancia de '-ar y '-an. El topónimo * A l b ă r u m es reconstruído por Philipon creyéndolo ibérico ${ }^{37}$. Meyer-Lübke y, según él, Nunes y Sachs le dan origen germánico ${ }^{38}$. Pero ni una ni otra hipótesis se avienen con el conjunto de formas ni con la distribución geográfica de ellas.

Abunda como nombre de lugar Alvaro Coruña, Portugal, el Campo de Hazálvaro (Faz-Alvaro, JuAn RuIz, copla 1187b) Segovia, Velascálvaro Valladolid; además los derivados Albarello Galicia, A l b a r elios año 9o7 hoy Albarelhos Villa-Real, Porto, Viseu, Albarillo Salamanca, Albarells Barcelona; Alvarin, Albarin Oviedo, Galicia, Alvarim Portugal (ya escrito con la grafía A l v a r i n en documento latino de $974^{39}$ ); Alvariza, Albariza Galicia, Oviedo, Ávila, Alvariça Vianna, Aveiro; Alberuela Huesca, Alberola Lérida; Alba. redo Galicia, León, Albareda Lérida; Albarón, Albarona Galicia, Alvarão Porto. En Italia Alvaro Verona, Alvari Liguria, Alvaro monte en Cerdeña; y los derivados Albarello Córcega, Albarelle Verona; Albarola Piacenza; Albaredo, Albareto, Albareda; Albaron, Alberone, Alberoni, muchos. En el Sur de Francia, A l b a r a s c u s, posesión de la iglesia de Marsella en $839^{40}$; l'Albarède Tarn, Albarède Dordogne, Aubarède Hautes-Pyrénées, les Albarèdes Tarn-et-Garonne, Albaret Gers, Lozère, Aubaret Puy-de-Dôme ${ }^{41}$.

En la lengua común el bajo latín usaba como derivado de a $1 \mathrm{~b}$ u $\mathrm{s}$ el adjetivo a l bă ru s 'blanco', según un glosario greco-latino ${ }^{42}$, y ese a l b ă r u s significó también el 'álamo blanco', de donde el italiano álbaro, álbero, siciliano árbanu; it. albereta 'alameda'; tam-

36 "Petrus Bragalensis episcopus" en doc. leonés de 1072 (España sagrada, vol. XXXVI, Apéndice $\left.26^{\circ}\right)$. Bragaa en Port. Monum. Hist., Scriptores, págs. 22, 26, 198, etc., textos de los siglos XIV y xv; documento de $125^{8}$ en A. A. CoRTrsão, Onomástico medieval portugués, 1912, pág. 57, quien no registra ejemplo ninguno con $-l$-, sino sólo Bragaeses año $125^{8}$.

37 E. Philipon, Peuples primitifs, 1925, pág. 235.

38 MeYer-LübKe, Romanische Namenstudien, vol. I, Wien, 1904, pág. 8; J. J. Nunes en HMP, II, págs. 584 y $58_{5}$; Georg SAchs, Die germanischen Ortsnamen in Spanien und Portugal, 1932, págs. 27-28 (véase para varios derivados que aquí no indico).

39 Cortesão, Onomástico, pág. 19.

40 D'Arbois de Juvainville, Premiers habitants de l'Europe, vol. I, 1889, pág. 364 .

41 A. Longnon, Les noms de lieu de la France, 1920-1929, §§ 2902 y 2341.

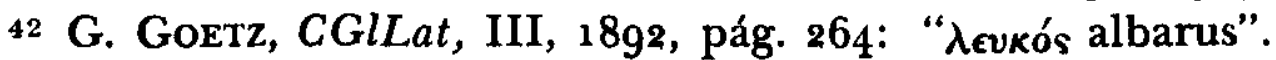


bién it. álvano 'fresno'43; cat. albareda, albereda, aubareda 'alameda', sitio poblado de albas 'álamos'. Las formas con $n$ ocurren también en toponimia: Albano lugar y monte en Sicilia.

Muchos de estos topónimos aludirán a la blancura del terreno, lo mismo que Albos, Albosa, Albero, Albar, Albear; otros aluden al álamo, como es evidente cuando toman el sufijo colectivo: Albareda.

El arraigo de a l b ă rus en la lengua latina vulgar se observa en nombres personales salidos de él: A $1 \mathrm{~b}$ a r i n u s (CIL, XII, 1 157), A l barenius (PERIN), que aparecen en inscripciones latinas; después, en la Edad Media, se usó mucho el nombre Alvaro, no sólo en España, sino también en el Languedoc ${ }^{44}$.

Otro ejemplo de la alternancia '-ar, '-al lo vemos en el nombre de la actual Nájera, ciudad que sólo comienza a sonar en el siglo x, cuando se funda el reino de Navarra.

En el latín de los siglos $\mathrm{x}$ y $\mathrm{xI}$ hallamos $\mathrm{N}$ a ja $\mathrm{ra}, \mathrm{N}$ a ga ra,

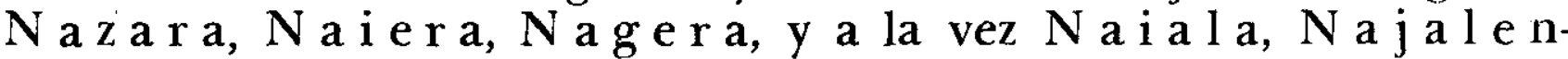
$s$ i $s^{45}$.

También se ven las formas con $l$ y $n$ arrinconando a la forma etimológica con $r$, en el nombre personal $\mathrm{C} h \mathrm{r}$ is t ŏ $\mathrm{ph}$ ŏ $\mathrm{r}$ u s que asimiló su terminación a nuestros sufijos y se hizo ${ }^{*} \mathrm{C} h \mathrm{~h}$ i s t o phă l u s > G h ris tŏ uă l u s año 939 (León) > Cristuébalo 824 (Campó) > Cristuébal 1103 (Burgos); y sin diptongación, Cristóvalo 1074 (León) ${ }^{46}$, moderno Cristóbal; por otra parte, en Portugal se hizo Ch rist ovăn us año $1220>$ Christovão $1258^{47}$, que es la forma portuguesa moderna.

\section{EL SUFIJO 'ar EN LA LENGUA COMÚN}

Comprobada así por la toponimia la antigüedad del sufijo '-ara, '-aro y varias alternancias '-ano, '-alo, aduciremos algún ejemplo en la lengua común, además de los que la toponimia nos ha hecho recordar.

El sustantivo común más antiguamente documentado es cáscara, usado como nombre de dos lugares hoy desconocidos, nombrados en un documento latino de Sahagún, del año 956, "Kascaras et Kas-

43 REW, 318. En DU CANGe, albareta, albereta; y también albarellus, cat. albarell 'canastillo' en el Diccionari Aguiló.

44 P. Skok, Die mit den Suffixen -acum, -anum... südfranz. Ortsnamen, 1906, págs. 50-51. Schulze, Eigennamen, pág. 119, nota 1 , respecto a $\mathrm{Al}$ b ar e $\mathrm{n}$ i u s no tiene en cuenta la gran difusión de a l bă rus en la onomástica.

45 En España sagrada, vol. XXXIII, 1781, págs. 195-214; Cartulario de San Millán, ed. cit., Indice, especialmente págs. 66 y 94; Docum. de Ramiro I, Indice.

${ }_{46}$ Recojo estas formas en Origenes del español, $\$ \S 23_{2}$ y $45_{1}$.

47 Ambas formas en Cortesão, Onomástico, págs. 83 y 97; abundan Cris. toualo año 964 , Christoual 1087 , etc. en Portugal. 
carellas"; es nombre derivado de casco, casca. - Después, en el siglo xiIr, Berceo usa gállara (San Laurencio, 22d), a la vez que el simple agalla (Duelo, 19c; Milagros, 87c), y lo usa en una de esas frases populares que encarecen la negación: "non daba una gállara por omne losengero"; después ese gállara no se registró más en la literatura, y no entró en el Dicc Acad. hasta la $16^{\mathrm{a}}$ edición (1939), con ocasión de haberse recogido informes sobre el uso de la voz en varias regiones. - Otras voces de escaso uso en la lengua registra el Diccionario oficial, como alicántara, sinónimo de alicante 'víbora', gárgara y varios más, de difusión muy limitada geográficamente. Dialectales son áscuara 'ascua', pómpara 'pompa, burbuja', en Asturias; tándara 'tanda, vez, turno', en 'Toro; tállaro 'tallo', en Salamanca; chátara 'abarca', en Santander y Palencia, 'pezuña' en Valladolid.

Notables son sobre todo los que mejor prueban la vitalidad del sufijo, formaciones tardías no derivadas de un sustantivo, sino de un verbo: picaro, del verbo picar (el "pícaro de cocina"), cuyo acento nos es necesario aunque pensemos como desde antiguo se piensa que el gentilicio picard intervino semánticamente; guácharo 'hidrópico o encharcado en agua', del verbo aguachar ${ }^{48}$, páparo 'papanatas, papahuevos, papamoscas'; en Asturias, donde el sufijo cuenta con muchos derivados, nos da deverbales como pitara 'silbato', de pitar; báilara 'perinola', de bailar.

En portugués podemos citar cáscara, gándara, liparo, dialectales bôlhara, búsara, pólvaro, uvas pássaras, gájaras, tánjara ${ }^{49}$.

El calabrés acúmmaru, siciliano agúmaru, conservan el vocablo

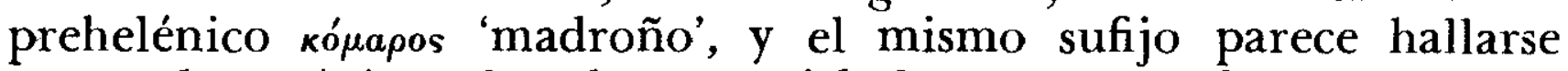
en nombres alpinos de arbustos o árboles como tsondar y gembar ${ }^{50}$. En vez de gazza 'pega, urraca', el toscano conserva el anticuado gázzara; en vez de malvizzo, malvits 'tordo, malvís', se halla en los Abruzos malvitzera; en vez del it. galla, se dice en Cerdeña ládụara (AIS, III, 504, 494, 591), que corresponde al esp. gállara; también codatsintsara 'coditrémola', 'aguzanieve' (AIS, III, 498). - La vitalidad de '-ar se advierte cuando ese sufijo invade '-al o'-an: lígur ganófaru, lombardo galófar, siciliano galófaru, veneciano garófolo, it. garófano 'clavo, capullo oloroso' < c a r y ó p h y 11 u m (AIS, III, 641); comp. néspora por néspola, néspala (AIS, VII, 1277), como en español niéspera por niéspola.

48 No me detengo a documentar aquí mis afirmaciones, pero diré que el simple guacho no es origen, sino al contrario, es regresión de guácharo; no fué acogido en el Dicc. Acad. hasta la $12^{\text {a }}$ ed. (1884). En Andalucía guacho conserva el significado primitivo de 'enaguazado, empapado en agua'.

49 Lo desconocido que es el sufijo '-ara se ve en que LeIt'E DE Vasconcellos ( $R L u$, VIII, 1903, pág. 62) explica tánjara como derivado de tanja (de tanger), con intercalación de $r$, *tánja. Véase el citado trabajo de Hubschmid, pág. 249, y además $B H i$, VII, 1905, pág. 195, y $R L u$, II, 1891, pág. 243, y V, 1898, pág. 90 .

50 Bertoldi, Mél. Van Ginneken, págs. 168 y 164 . 
EL SUFiJo '-an

He aquí algunos nombres toponímicos asociables entre sí:

Turuégano en el siglo xv, modernamente Turégano Segovia, de un céltico $T u$ rŏ ca, en el Itinerario de Antonino $T$ u ro qua al Sur de Pontevedra. - Várzana en Liébana, documento del año $1282^{51}$, y en lo moderno Bárzana Oviedo (diecisiete lugares); Bárcena, Barcenilla Oviedo (cinco lugares), León (dos), Santander (dieciséis), Burgos (ocho), Palencia (dos); Barcia, Barciela Galicia (cuarenta y dos), Occidente de Asturias (dos); Varzea, Varziela Portugal, numerosísimos. En documentos latinos de León y Castilla, B a rc en a años $863^{52}$ y 1092 , V a rzen a $1098,1114^{53}$, en Portugal V a r z e n a 959, V a r z e n e l l a 1014 (CORTEsão, Onomástico). El nombre común bárcena 'bardal de una cerca, seto' se conserva en Santander, y el simple barza 'zarza' en Aragón (Borao) 'tejido de ramas para cercar un predio' (Echo), de donde barzar 'cercar un campo con un seto' (Ansó); barzal 'zarzal, terreno cubierto de maleza' Aragón y Colombia (Cuervo, Apuntaciones, § 860); en portugués varzea significa 'terreno llano, cultivado', y en la India portuguesa 'arrozal'; de todo lo cual resulta que el significado fundamental de várzena es 'heredad cercada con un seto'. - Sámano y Resámano (= 'río Sámano') Santander; comp. Sama Oviedo. - Truébano Oviedo (cinco lugares), León (uno); se conserva en Asturias el común truébanu 'colmena, tronco de árbol ahuecado de roble o de castaño que se usa para colmenas o como vasija para hacer la colada'; en Tras-os-Montes, troba 'grande concavidade nos troncos dos castanheiros' ( $R L u, \mathrm{I}, 1887$, pág. 220). En Lugo hay ocho lugares Trobo, y en el Occidente de Asturias Trovo, mientras en las otras tres provincias gallegas no aparece este topónimo, lo cual delimita bien la extensión geográfica de la voz. El río Trueba de Burgos tiene origen distinto, T r i oba. - Argüébanes Santander, A rg ov a n e s año 875 y 952, A r g o b a n e s $103^{54}, 1058$; comp. Argovejo León. Cándana, Cándano, ya tratados.-Ódena Barcelona; comp. Odén Lérida.-Solórzano Santander; comp. Lorza Ålava, etc.

Los derivados de sustantivos latinos o románicos son muchísimos:

Huércanos Logroño, H o r c a n o s año 894, de ŏ r c a 'vasija, cavidad'; comp. Valluerca Burgos, Álava (Origenes del español, 1926, $\$ 61$ bis). - Ciérvana Vizcaya; comp. La Cierva Cuenca, Ciervos Åvila, Zamora. - Prádanos Burgos (dos lugares); Prádena Segovia,

51 E. StaAff, Dialecte leonais, pág. 104.

52 Cartulario de San Millán, ed. cit., pág. 10.

53 Cartulario de San Vicente de Oviedo, ed. del P. Serrano, 1929, págs. 118,126 y 146 .

${ }_{54}$ Cartulario de Liébana, ed. Sánchez Belda, 1948, págs. 9, 66, 98 y 104; en los primeros documentos abunda la forma Argonaues que será mala lectura, confusión de $n$ y $u$, más bien que pedantesca metátesis alusiva a la leyenda de los Argonautas. 
Madrid, Guadalajara; Pládano Oviedo; comp. Prada, Prado, Pradilla. - Estrígana Guadalajara; comp. Estrigueiras Coruña; de e s t r ì g a 'andana, ducha de heno segada, hilera, surco', gall.-port. estriga 'porción de lino para hilar'. - Liédena Navarra, del adjetivo l a et u s; comp. en Italia el monte Lieto (y en España los topónimos Alegria, Alegranza), y Ledigos Palencia $<1$ a e t if i c u s ${ }^{55}$, que antiguamente debió de ser Liedigos, pues en castellano medieval se usó el adjetivo liedo antes de propagarse el portuguesismo ledo. Yérbano Oviedo. - Fréscano Zaragoza. - Pedruégano Badajoz. - Los Lómbanos, El Píngano Vizcaya. - Pelúgano Oviedo; en Italia Pelu. go Trento, Peluco Calabria. - Perrétano Álava, etc.

En Italia B r a d a n u s, río que separa la Lucania de la Apulia, en el Itinerario de Antonino, hoy Brádano, y un lugar llamado Bra. danello en la Basilicata. - Bárgano en Milán; comp. en la Tabula Veleiana (CIL, XI, 1147 ) B a r g a ${ }^{56}$, y hoy Barga en Toscana, Barghe en Lombardía, y en España Barganáz Oviedo, Barga Pontevedra, La Barga Álava, Bargas Toledo, Las Bargas Logroño; hablaremos después de los apelativos bárgano y barga. - Lóttano en Lombardía, a la vez que Lotta, Lota, Lottas. - Cárcano varios. - Cárpano y Carpaneta. - Silano a la vez que La Sila.

En Sicilia Albana, Albano a la vez que Alvaro, ya tratado.

En Cerdeña Arzana, Abáltana, Bolótana, Lácanu, Pámpana, Tálana, Tíana, Ússana a la vez que el ya tratado Ússara.

En Córcega Pátana, Bástani, Códani ${ }^{57}$.

Añádase $R \mathrm{~h}$ ŏdăn us $R$ ŏdănus, nombre de varios ríos en la región del Rin, en Francia y en el Norte de Italia $^{58}$, de los cuales el principal es el que separaba a los íberos de los lígures según Avieno. Se usó $\mathrm{R}$ od a $\mathrm{n}$ u s como nombre personal fuera y dentro de España ${ }^{59}$. También Ródano designa un lugarcillo próximo al Este de Milán y un caserío en Calabria, al Sur de Catanzaro. En España Rodanillo, lugar de la provincia de León, y en Portugal en documentos medievales $\mathrm{R}$ o d a n o y $\mathrm{R}$ o t a $\mathrm{n}$ o año 1186 (CORTESÃo), y actualmente varios Rodão, cuya acentuación me es desconocida; en el centro de España el topónimo parece tuvo uso tradicional o popular, cuando la Primera crónica general de 1289 llama al famoso río de Francia con nombre conforme a la correcta evolución fonética castellana, el Ruédano ${ }^{60}$.

$5 \tilde{5}$ Esta etimología que doy se funda en un documento de 26 de septiembre de 1028: "in territorio Coza... inter duos rivulos Karrione et Aratoi, in loco predicto ubi dicunt Letificus" (en Ferreiro, Historia de la iglesia de Santiago, vol. II, Apénd. 89). La identificación que hago es segura, pues Ledigos está junto al río Cueza.

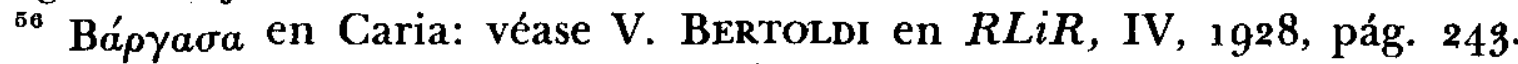

57 Bottiglioni, Elementi prelatini nella toponomastica corsa, 1929, págs. 35,36 y 72 .

58 Holder, Alt-celtischer Sprachschatz, vol. II, col. 1223.

59 Holder, col. 1222 , inscripciones de Lisboa, Álava y Palencia.

${ }^{60}$ Primera crónica general, págs. $105 b, 38 ; 322 a, 42$, etc., cinco veces, y sólo en la pág. $68 a, 41$, usa el Rodano. 
En la lengua común hay que citar primeramente la palabra que nos sorprende en la toponimia de Milán, bárgano, escrita con $v$ en el Dicc. Acad., várgano 'estaca clavada que en fila con otras, sirve para hacer sebes', voz documentada ya en el siglo Ix en Asturias (Origenes del español, 1926, $\S 61$ bis) y cuyo simple barga 'choza formada con bárganos y ramas' tiene uso en español, en portugués y en dialectos alpinos $(R E W, 958)$, y aún creo que pertenece a este grupo el fr. barge 'montón de heno', almiar formado en torno de un bárgano. - légano, que el Dicc. Acad. no registra hasta la $12^{\text {a }}$ edición (1884), mientras incluye su sinónimo légamo en la primera edición (1734), con texto de Calderón, por ser hoy la voz corriente; sin embargo, la forma primitiva es con $n$, según se ve, en la toponimia, en el diminutivo Leganitos, nombre precioso de una calle de Madrid (hasta que lo suprima nuestro Ayuntamiento en su furia de neologismo callejero, para inmortalizar alguna celebridad contemporánea); la $n$ primitiva se ve también en Leganiel Cuenca, otro diminutivo de tipo mozárabe, y en Leganés Madrid < l e g an e n s e. La forma simple sin sufijo, *lega ${ }^{*} \operatorname{lego}$, se ha perdido a causa de su homonimia con el derivado de la i c us de uso tan general; procede del céltico ${ }^{*} 1$ i g a 'poso, sedimento, cieno', esp. y port. lia, fr. lie 'heces del vino', monferrino liga 'fango' ${ }^{61}$; los romances vacilan en reflejar $i$ tónica abierta o $i$ cerrada. - tútano, tuétano, formas ya documentadas en la lengua medieval (Corbacho, NebriJa), port. tútano, de la base ${ }^{*} \mathrm{t}$ u $\mathrm{t} t$, que, con otros sufijos átonos, aparece en el italiano tùtolo 'zuro, carozo, troncho de la panocha' y en el sardo tútturu 'rollo de pasta' ${ }^{22}$. - carámbano, forma corriente hoy, y en los diccionarios desde el de Nebrija, pero carámbalo usado por autores de los siglos xvi y xvir (Dicc. hist., vol. II, 1936, pág. 703a); el simple carambo 'carámbano' se usa en Lugo ${ }^{63}$; la forma castellana carama 'escarcha' se usa en Palencia ${ }^{64}$. - truébano y troba, extendidos por Lugo, Asturias, León y Nordeste de Portugal, como ya queda indicado. - peruétano documentado en NebriJa, y, con inflexiones de la inicial (causadas por la $u$ ), piruétano 'pera silvestre'; derivado de * perueta, uno de los escasos ejemplos de otro sufijo prelatino, - o t to. - burdégano también en NebriJa, port. bordégão, subderivado de otro sufijo átono *bórdego de borde < b u rdus. - búzano, usado en los siglos xv y xvI al lado de buzo. - retruécano en vez del simple *retrueco o *retrueque, de retrocar. - tángano, tángana, con igual sentido que el simple tango, del verbo tañer, port. tángão; con otro sufijo átono, tángala 'juego de tejo o chito' Colunga (Oviedo). - médano y meda, port. medão y medo, de m e ta . - ojáncano Santander, lo mismo que

61 J. Jud en $B D R$, III, 1911, pág. $78 ; R E W, 5021$ y 5029.

62 REW, 9017; MeYEr-LüBke, que admite sin dificultad la alternancia '-ulo '-uro, desconoce '-ano, hallando "dificultad formal" para tútano.

63 Vocabulario de Meira, por Anibal Otero (ms. que debo al autor).

${ }^{64}$ El Dicc. Acad., 16a ed. (1939), incluye esta voz sin nota de provincialismo, lo cual me parece inexacto. 
ojanco 'cíclope', registrado por la Academia. - bichángano 'bicharraco, animalucho' Huelva. - zángano, tártano, etc., etc.

Asimilación de otros esdrújulos ya en el período primitivo del idioma: sárçano en documento de 974, y en la Primera crónica general traduciendo el lat. $\mathrm{s}$ a $\mathrm{r} \mathrm{c}$ in a; este paso de $\mathrm{s}$ a $\mathrm{r}$ c in a sárçano es, pues, posterior a la asibilación de $c e$, $c i$. En español y portugués pámpano < pampinus; el italiano usa pámpano y pámpino a la vez. A la época del latín vulgar debe remontar la a en cŏ $\mathrm{ph}$ in u >cuévano, pues el italiano dice también cófano.

Del uso de este sufijo en Italia hallamos ejemplos dialectales: en vez del llano baleno, hallamos varias formas populares: kalúgano, arlúddzano, škalúdzano ${ }^{65}$, con el carácter imitativo que observamos en relámpago. En las montañas del Norte lézena 'arrastradero para troncos en la montaña', de leza 'narria, basna'; y con igual significado 'arrastradero' hay rižena y el simple riza ${ }^{66}$. Hallamos también asimilación de otras terminaciones esdrújulas: además de pámpano y cófano ya citados, tenemos tónfano 'hondonada', del longobardo $\mathrm{t} \mathrm{u} \mathrm{m} \mathrm{p} \mathrm{f} \mathrm{i} \mathrm{lo}(R E W, 898 \mathrm{o})$, y abruòtano abròtano $<\mathrm{a} \mathrm{b} \mathrm{r}$ ŏ $\mathrm{t}$ o $\mathrm{n} \mathrm{u} \mathrm{m}$, que ya en los glosarios antiguos y en latín medieval aparece bajo la forma a b r ota $\mathrm{n} \mathrm{m}$ (Goetz, Du CAnge).

EL SUFijo '-al

Nombres toponímicos varios:

Carta la, capital de los Olcades (al Sur de la Carpetania), ci. tada por Tito Livio, sin que sepamos la cantidad de la segunda $a$, pero debía de ser breve a juzgar por el Cártala de Salamanca. C a m a la en el Itinerario de Antonino, estaba hacia Sahagún; comp. Camaleño Santander; como nombre personal abunda mucho Cam a l us, Ca ma la, en inscripciones del Noroeste de España (Portugal, Cáceres, Astorga), y no en otras provincias del Imperio; sin embargo, hay también en un texto griego $\mathrm{K}^{\mu} \mu a \lambda{ }^{6}{ }^{67}$. - Arévalo Âvila, Soria, León, Los Arévalos Salamanca, Arevalillo Ávila, Salamanca; el simple A r e v a es el nombre de un río no identificado del cual, según Plinio, tomaron nombre los Arevácos. E1 Arévalo de Soria y acaso el de Ávila pertenecen al territorio de los Arevacos, pero no los otros, que suponen la base A r e va repetida en otras regiones. Arévalo lleva sufijo ibérico, mientras Arevaco tiene sufijo céltico como corresponde al nombre de una tribu celtibérica. $-E l$ Bóvalo, siglo xv, en la cuarta Serranilla del Marqués de Santillana, el Bóalo actualmente, pueblo de la provincia de Madrid; con o cerrada sin diptongar (por tanto, no de b o v e). Se usó también como nombre de varón $\mathrm{B}$ o v a l u s, según aparece en una inscripción de Chaves (CIL, II, 2485). - Andévalo Córdoba, Huelva. - Búrdalo río de Cáceres; Abalos Logroño; Nódalo Soria; Névalo Córdoba, etc.

65 AIS, II, 392; hay tamibién formas con $i$ postónica: alúdzino.

66 AIS, III, 535 (también rizina); REW, 4996; Bertold en Romanica Hel. vetica, XX, 1943, pág. 235 .

67 Citas bibliográficas en Holder, vol. I, col. 707 . 
De nombres comunes románicos:

Huértalo Huesca, a la vez que muchos topónimos Huerto, Huerta. - Nuévalos Zaragoza, a la vez que muchos pueblos con el nombre Nuevo, Nueva. - Bárbalos Salamanca, y el simple Barba en los túrdulos de la Bética (MAdoz; Holder), Barba Salamanca, Barbas Portugal. - Cúcalo de donde Cucalón Teruel, Valencia; en Italia muchos montes llamados Cúccaro, Cucco; en Portugal muchos lugares Cuco, Cucos. - Grávalos Logroño; comp. Graba Pontevedra, etc.

En la toponimia italiana hallamos Andalo a la vez que Anda; Ciófalo a la vez que Cioff; Gávala, Fánfalo. En Cerdeña, Cávala, Cátala, Simala, Másala. En Sicilia Búcalo. En Córcega Gárgalo ${ }^{68}$, y con sufijo '-an, Garganello.

Probablemente el - ŭ $\mathrm{l}$ u latino comunicó al '-alo prelatino un valor de diminutivo afectivo. Los dos eran sentidos como elemento accesorio en los nombres toponímicos, que se podía añadir o quitar a voluntad. El diminutivo latino de $\mathrm{T}$ o l e t u $\mathrm{m}$ Toledo fué muy usado hasta en el siglo xiI, Tolétula, Tolétola, Tolédola; los árabes dijeron siempre Toláitola, el catalán Tolèdol; pero esta forma, afectiva- sin duda, no prevaleció. Lo mismo sucedía con el sufijo prelatino: un pueblo de Valladolid, que hoy se llama Gordaliza, era también llamado Gordalizala en el siglo XI (Origenes del español, $1926, \S 61$ bis), forma que luego cayó en olvido. Burgos fué llamado igualmente ${ }^{*}$ Búrgalos, pero de esta forma no me es conocido ningún rastro, excepto el adjetivo burgalés, que el Poema del Cid usa al lado de burgués, y que, sin sufijo '-al, desapareció para evitar confusión con el sentido general de ese adjetivo, y así se salvó de la muerte el adjetivo de sufijo prelatino.

De la lengua común tenemos un importante ejemplo en la voz, extraña al latín, s c a n d ă la, que recoge Plinio, cuya forma simple s c a n d a vemos en un fragmento de época visigótica (siglo viI?) conservado en la Crónica "Albeldense" (mejor Ovetense), año 88 3 " De la forma simple procede el español corriente escanda, mientras que de la forma con sufijo proceden el ast. local escaña y el port. escándea; el cast. y cat. escandia deben de proceder de portuguesismo medieval ${ }^{70}$. - En la lengua actual tenemos también bonitalo con igual significado que bonito 'pez'. - pezpitalo, sinónimo de pezpita 'aguzanieve', donde la cola trémula del ave provoca el esdrújulo en función imitativa sinestésica (como arriba vimos el it. dial. coda-

68 Acentuado en Bottiglioni, Elementi prelatini..., pág. 55; sin acento en el Indice del Touring Club, que carece de acentuación en muchísimos más nombres.

69 España sagrada, vol. XIII, 1816, pág. 435; Mommsen, Chronica minora, 1894, pág. 371 (MGH); Goetz, CGlLat, VII, 298a, tiene por inadmisible la forma s c a n d a la de un glosario (!).

${ }^{70}$ En los Miráculos romanzados de Santo Domingo (hacia 1285) se halla "escandia roja aspera... pan de escandia bermeja" (en S. dE Vergara, Vida de Santo Domingo, 1736, págs. 213, 216, 204). Pudiera ser también un leonesismo, pero no creo corriente en Asturias la forma escandia con $i$ parasitaria. 
tsintsara). - arrejáquele en Salamanca, del arabismo arrejaque 'vencejo'. - frágala en Murcia, por el simple fraga 'heces, lias del vino' usual en Alicante. -Varios verbales: arrepápalo 'buñuelo'; alárgalo 'colgajo' en Andalucía (comp. el Lárgalo, caserío de Cádiz); escárbalas 'cosquillas' en Mombeltrán (Ávila); rápalo cierto juego de Extremadura, etc.

Asimilación de otros esdrújulos:

El sufijo latino - ŭ l mantenía en la época preliteraria del espanol multitud de veces la $\breve{u}$ postónica, sea por tendencia cultista sea por influjo del sufijo '-al: ríbolo 'río' $<\mathrm{r}$ i v ŭ $\mathrm{l} u$, tábola, artigolo (ejemplos múltiples en Origenes del español, $\$ 32_{3}$; hoy sólo subsiste, como arcaísmo corriente, péñola $<$ p e n n ŭ la), y se producían dobles formas: c e r n i c ŭ $\mathrm{l}$ u m 'ave que vuela con movimiento basculante como de criba' > cernicolo usado por don Juan Manuel, cernigolo usado por Alfonso el Sabio, cernicalo forma que hoy subsiste. - En más casos la vocal prelatina $a$ es la única conocida desde la época preliteraria del español; la vocal latina $o$ no dejó rastro. Así, al lado de murciego (Alexandre, $2013^{c}, 2015^{c}$ ) $<\mathrm{m}$ u re c a ecu, debió de existir un *m u re c a e cu lu, pero sólo nos son conocidas las formas con a postónica, murciégalo, que desde comienzos del siglo XiI se documenta en un préstamo al árabe murži $k a l$, y con otro sufijo átono murciégano en Asturias, Salamanca, Zamora. $-\mathrm{De}^{*} \mathrm{~s} \breve{\mathrm{u}} \mathrm{b} \mathrm{t} \breve{\mathrm{u}} \mathrm{l} \mathrm{u} \mathrm{s}>$ provenzal sótol ( $\left.R E W, 8401\right)$, el español primitivo hizo sótalo, documentado en 955 y 980 y en la Biblia del siglo Xv traducida por Mose Arragel; pero la forma hoy subsistente es sótano. - El diminutivo o $\mathrm{v} \breve{\mathrm{u}} \mathrm{l} \mathrm{u} \mathrm{m}$ que da el it. uóvolo óvolo 'seta, hongo, óvalo' da en español óvalo y óvano, figura geométrica.

En los dialectos italianos abundan los derivados con sufijos '-al, por ejemplo: pipitala por pipita (AIS, VI, 1141), coniyyalu por coniglio (ibid., 1120); o suplantando a - ŭl, - $1 \mathrm{l}$ etc., capétsalo por capézzolo (AIS, I, 127); núvala por núvola (II, 364), néspala por néspola, ya tratado, garófalo por garófano, arriba tratado, pámpalı pámpala por pámpino pámpano (AIS, VII, 1309).

El SUFijo'-ag

Este sufijo se distingue de los tres anteriores en constar de una consonante oclusiva, y no continua. Lleva vida más independiente que los otros tres.

Primeramente pondremos algunos ejemplos toponímicos:

T a r r a g a Plinio, Tápoaya Tolomeo, ciudad de los Váscones; Tárrega Lérida; Tárrago apellido; tárrago planta, especie de salvia; cat. tärrach planta. - * T a măg a, de donde el nombre de un pueblo de la Galecia, T a ma g a n i, mencionados en una inscripción de Chaves, año $79 \mathrm{~d}$. C. (CIL, II, $2477=5616)$, pueblo ribereño del río Támaga o Támega que corre por Orense, pasa por Chaves y afluye 
al Duero; Támagos, Tamaguelos Orense, ambos sobre el río Támaga. Este '-aga es identificable acaso con el sufijo vasco -aga colectivo (cf. C. C. UHLENBECK en RIEV, III, 19o9, pág. 4) que solemos pronunciar esdrújulo en algunos nombres, aunque no sabemos con qué razón, porque el acento de intensidad no es vasco, y así tenemos Lizárraga o Lizarrága indiferentemente (Navarra, Guipuzcoa) 'fresneda', de lizarr 'fresno'; Lárraga (Navarra) 'zarzal'; Azcoága, Amézaga (Álava).

En lo moderno, prescindiendo de la multitud de estos nombres, propios de las cuatro provincias vascas, los topónimos '-aga escasean:

Párraga apellido; comp. Parga pueblo y río de Lugo. - Jábaga Guenca. - Huélaga Cáceres, también con terminación masculina Huélago Granada, Almería, y con cambio de sufijo Huélamo Cuenca, Huelma Jaén, de una base ol; comp. Huel o Güel Huesca. - La terminación masculina es más frecuente: Rábago Santander; comp. Rabo, Rabal Galicia, Portugal, Rabé Burgos, Rabasco Rabasca Portugal. - Sástago Zaragoza. - Obétago Soria. - Návagos Burgos, derivado del sustantivo prelatino $\mathrm{n}$ a va, comunísimo en toponimia. Cántagos Soria, frente al simple Canto, Cantos, los Cantos.

En la lengua común hallamos en el período preliterario la voz có rn a g o 'cauce, canal, acequia, reguera' en documentos latinos de Carrión 1057, y más tarde cuérnago 1234, 1240, en el mismo Carrión (textos en Orígenes del español, 1926, $\$ 61$ bis), donde el curso del río Carrión está desparramado en multitud de brazos cada uno de los cuales conserva el nombre de que tratamos, Cuérnago de Castillos, Cuérnago de Nogal ${ }^{71}$; derivado de c ŏ $\mathrm{n} \mathbf{n}$ u 'brazo de río'; comp. Cuerno 'arroyo' Sevilla, Cuerna 'riachuelo' Valencia. Desconociendo el sufijo '-ago, Meyer-Lübke (REW, 226ob) explica cuérnago como cruce de cuérrago con cuerno, pero tal suposición es innecesaria, teniendo en cuenta los demás derivados en '-ago. - Ciénaga, ciénago 'sitio lleno de cieno', de c a e n u m, con igual sentido de abundancia que el otro derivado, cenagal; también antiguamente ciénago significó lo que el simple cieno, como hoy en Salamanca y Palencia ciénago o ciégano 'lodo', donde el sufijo ha quedado sin función semántica ninguna. Derivados cenagoso y el verbo cenagar usado en el siglo xvI, y encenagar hoy subsistente. Una forma accesoria de todos los sufijos átonos lleva $e$ postónica, y así tenemos ciénega (Ercilla usa las dos variantes, con $a$ y con e) y encenegar, variedades usadas bastante en América, pero los diccionarios, desde el siglo Xvi, incluso el actual de la Academia, no conocen sino las formas en '-aga $a^{72}$. Sin embargo Srorm (Ro, V, 1876 , págs. 178 y 18 i) y Cuervo (Apuntaciones, 1907, $\$ 784$ ) explican la $g$ de ciénaga partiendo de un verbo *in ca enicare $>$ encenegar, de uso común ya en el siglo xv, sin reparar que esta derivación no explica la general firmeza de la $a$ en la sílaba ag-; y cuando Storm se ve obligado a

i1 Madoz, vol. V, pág. 6goa. Con el sufijo -ă c u hay Córnago (Logroño).

${ }^{72}$ Con muy raras excepciones: Terreros, en su Diccionario (1786), incluye cenegal, "anticuado" por cenagal. 
pensar en el sufijo dice: “On sait qu'il y a beaucoup de dérivés -ago proparoxytons de formation récente", pero esa modernidad es lo que continuamente venimos negando en estas páginas. - relámpago, ya documentado en la Primera crónica general de 1289 (pág. 574b, 40), y el verbo relampagar usado por Berceo (Santa Oria, 9oc) en vez del simple relampo y relampar que usa el Alexandre (1103b, 87a, 920b), derivado de 1 a m po y 1 a m p a r e 'brillar'. En portugués relâmpago y relampaguear han arrinconado a relampo y relampar que hoy sólo viven dialectalmente. En esta palabra se ve con claridad que la acentuación esdrújula del sufijo cumple, por efecto de una sinestesia, cierta función imitativa de la repentina fugacidad luminosa; hemos visto que el italiano dialectal usa también esdrújulos en este mismo caso. - luciérnaga, desde el Diccionario de Nebrija (luziernaga) y en los siguientes siempre con $a$ postónica, aunque existe como secundaria la forma luciérnega (Cuervo, Apuntaciones, $\S 784$ ), de lu cĕrna, cuyo derivado no me es conocido en castellano sino en portugués, luzerna, designando al mismo gusano de luz. - vástago, falsa grafía moderna en vez de bástago usado por Alfonso X (General estoria, ed. Solalinde, pág. $216 a, 33$ ), de b a s t u m basto (REW, 983). - rázago de raça (JuAn Ruiz, coplas $94 c$ y $5^{04 c}$ ). - huélfago, de huelfo que es usado en Andalucía y Extremadura (Alcalá Venceslada; Cejador, Tesoro, vol. IV, pág. 568) con el mismo sentido de 'huélfago', enfermedad de los animales. - galápago de galapo. - alhárgama metátesis del arabismo alharma 'ruda silvestre'. - buétago ya en 1386 en Ayala (Aves de caza), de donde botagueña 'longaniza hecha con asadura o buétagos de cerdo'; derivado de la raíz * b q t $(R E W, 1239 a)$, pues no creo pueda ser contracción de bofét-, bohét- como bueña de bofeña.

Asimilación de otros esdrújulos: c ŏ r r ŭg u s 'reguera, canal para lavar arenas auríferas', vocablo ibérico recogido por Plinio; se conserva fielmente en ant. port. córrogo año 1201 , pero predominaba ya entonces una forma con $a$ postónica o $e$, de donde procede cuérrago Burgos y Santander 'reguera, cauce', port. córrego corgo 'regato, ribazo' 73. - m ŏ r d i c u s > muérdago $(R E W, 568 \mathrm{oa})$. - Del it. raffica $(R E W, 7005)$, el español del siglo xvil decía ráfiga y ráfaga, siendo este último el que hoy subsiste. - Del it. tráffico, trafficare, el español dice tráfago y trafagar, usados ya en el siglo xv; port. tráfego, trafegar, cat. también desde el siglo xv tràfech, trafagar, trafegar.

En Italia hallamos también topónimos del tipo Córlaga en Toscana, a la vez que Corla en Bologna.

En la antigua Africa proconsular hubo dos ciudades episcopales A uzuăga (DE VIT), nombre al parecer derivado del de Auzui que llevaba otro lugar de la misma provincia de África, en la costa de la Gran Sirte (M. BeSNIER, Lexique); comp. también A u zĕa

73 Las formas citadas se hallan en el Dicionário de Nascentes, 1932, y en V. Cocco, "Ibero-rom. córrego", Biblos, XXVII, 1952, págs. 253 y 281. 
lugar de la Mauretania Cesariense, y los topónimos vascos Auzola, Auzoeche, etc., del apelativo auzo 'barrio'.

\section{RESUMEN}

Varias de las homonimias que hemos establecido entre topónimos de territorios muy apartados unos de otros, podrán ser casuales, sin duda, pero siempre queda la imposibilidad de que todas ellas lo sean.

Aún las correspondencias toponímicas escasas en número y muy alejadas geográficamente, se resisten a ser consideradas como fortuitas. Lo mismo alguna homonimia afro-hispana (Cáñar, Zújar, Auzúaga), o sardo-africana (Ússara, Ússana), o corso-africana (sápara) o sardo-hispana (Iscar).

Pero por cima de las homonimias totalmente idénticas (las aquí expuestas y varias otras) está el abundante uso de los mismos sufijos átonos '-ar, '-an, '-al, '-ag y aun '-am (que no me detengo a reseñar), todos empleades en las tierras occidentales del Mediterráneo, africanas o europeas, denunciando en ellas la existencia de lenguas prelatinas muy emparentadas entre sí. No conocemos lo que efectivamente sería en esas lenguas de sustrato la atonicidad que caracteriza a estos sufijos, pero al incorporarse tal procedimiento morfológico al latín resulta un acento de intensidad en la penúltima sílaba.

Todos estos sufijos fueron aplicados en los tiempos primitivos a vocablos de esas lenguas desaparecidas, conservados hasta hoy la mayoría de ellos tan sólo como nombres de lugar; continuaron esos vocablos con vida durante la expansión del Imperio romano, incorporándose al latín hablado y aun al escrito (s c a n d ă la), aplicándose a sustantivos latinos (a lbărus, cornăgus), de los cuales subsisten innumerables ejemplos adheridos a la denominación del terreno. Aún pasado el período de orígenes de las lenguas románicas, estos sufijos conservan alguna vitalidad aplicados a temas verbales (picaro, báilara, arrepápalo).

Pertenecientes a las lenguas de sustrato, estos sufijos vivieron ajenos a la alta cultura latina, relegados humildemente al vocabulario rústico, para denominar vegetales y animales indomésticos ( $g a ́$ llara, cernicalo), para expresar nociones relacionadas con la vida campestre (chátara, várgano, truébano); de ellos, pocos entraron en el caudal de la lengua más común y corriente (relámpago, vástago, sótano). El uso principal de estos sufijos es en la toponimia, siempre para designar lugares y ríos de poca importancia; B r a c ă ra, como nombre de una ciudad capital, es caso rarísimo.

A nombres de lugares formados sin sufijo átono, se aplicó el sufijo '-al con valor afectivo (Tolédola, *Búrgalos), pero este uso se olvidó en el curso del siglo XII. 
En cuanto al significado, estos sufijos tienen un valor antiguo abundancial (Cuétara, Cuéllar, ciénaga). Tienen también valor imitativo de repetición, rapidez, fugacidad (ráfaga, trápala, pezpitalo). Probablemente tienen también un valor afectivo, cuasi diminutivo (luciérnaga, murciégalo). Dado su uso principalmente vulgar, se aplican a conceptos peyorativos (páparo, picaro, bichángano). Pero por lo común esos valores particulares se desvanecen y estos sufijos quedan sin significación ninguna: cáscara pudo ser un colectivo de casca, pero hoy los dos vocablos vienen a ser sinónimos.

Estos sufijos son a veces intercambiables entre sí. Se hallan documentados desde la Antigüedad como diversos unos de otros y cada uno tiene su particular caudal de derivados, distinto del de los otros, pero a veces, según frecuentemente hemos visto, un mismo vocablo simple se presenta bajo doble o triple forma '-ar, '-al, '-an, y esto por dos razones: la primera es que los varios sufijos tienen equivalencia acústica, pues constan todos de una vocal a postónica seguida de una consonante nasal o líquida más la vocal final; y en segundo lugar, porque no tienen esos sufijos función semántica distinta y bien definida, sino un significado vago e impreciso, viniendo a ser por lo común una mera prolongación morfológica, esdrújula, de efecto simplemente auditivo. Los sufijos átonos forman, pues, un grupo, un sistema coherente, propio de las primitivas lenguas mediterráneas. Sin embargo, es preciso tener siempre en cuenta que cada uno de tales sufijos puede darse en otra lengua, diversa de esas mediterráneas; la objeción hecha por HuBschmid, citada en nuestra reseña bibliográfica del comienzo, puede aún extenderse más.

Madrid.

Ramón Menéndez Pidal 